\title{
Glucaric acid as an indicator of use of enzyme-inducing drugs
}

\begin{abstract}
The usefulness of urinary glucaric acid determinations to measure enzyme induction by drugs was investigated by correlating its excretion rate with the daily drug regimen of 100 hospitalized patients. The urinary excretion of glucaric acid was higher in patients than in normal controls. Patients treated with enzyme inducers excreted more glucaric acid than patients not getting them, as well as more than normal controls. In patients on multiple-drug therapy, the effect of small doses of known enzyme inducers was masked, but even here relatively high doses of potent inducers significantly increased glucaric acid excretion. The results also suggest that urinary excretion of glucaric acid may have value as an indicator of the use of certain drugs by patients when such information is not revealed by the history.
\end{abstract}

\author{
Eero A. Sotaniemi, M.D., Fedor Medzihradsky, Ph.D., and \\ Gudmundur Eliasson, M.D. Ann Arbor, Mich. \\ Departments of Internal Medicine, Biological Chemistry, and The Upjohn Center for \\ Clinical Pharmacology, University of Michigan Medical Center
}

Induction of the liver microsomal hydroxylating enzymes by drugs and environmental chemicals is well known in laboratory animals. ${ }^{6}$ The influence of enzyme induction on human drug-metabolizing capacity is less well documented. Little is known of the extent of this phenomenon in hospitalized and multiple-drug-treated patients, probably because methods to investigate enzyme induction in man are limited. The activity of drug-metabolizing enzymes has been assayed in liver speci-

\footnotetext{
Supported in part by a Fogarty Fellowship Grant No. 11 FO 5 TWO1777 and United States Public Health Research Grants Nos. 2 P11 GM15559 and RR 05383-11.

Presented in part at the annual meeting of the American Society for Clinical Pharmacology and Therapeutics, March 22-23, 1973, New Orleans, La.

Received for publication May 18, 1973.

Accepted for publication Aug. 18, 1973.
}

mens obtained during abdominal surgery ${ }^{2}$ and in needle biopsy samples. ${ }^{20}$ The latter technique is contraindicated in most acute cases; the former an uncommon opportunity.

The disappearance rate of test drugs ${ }^{19}$ does not necessarily reflect the total activity of drug-hydroxylating enzyme in patients on multiple-drug therapy ${ }^{4,22}$ because these drugs may compete with the test drugs for the same metabolizing enzyme system. ${ }^{14,25}$ Genetic differences in human drug metabolism also complicate the interpretation of drug disappearance rates. ${ }^{26,27}$ The urinary excretion of glucaric acid, a product in the glucuronic acid pathway of several species of animals as well as man, ${ }^{8,15}$ parallels the activity of drug-hydroxylating enzymes, ${ }^{1,5}$, ", 28 which provides a con- 
venient approach for detection of enzyme induction in man. ${ }^{9-11}$ The present investigation was undertaken to study the ability of glucaric acid determination to reflect drug-inducing therapy of hospitalized patients.

\section{Material and methods}

Subjects. The 100 subjects investigated, aged 18 to 80 years, were divided into three patient groups. The first group, under treatment in the Clinical Research Unit (CRU) of the University of Michigan Hospital, had the following categories of disease: endocrinologic (17), cardiovascular (11), collagen diseases (8), and gastrointestinal (5). The second group, consisting of 41 predominantly acutely ill patients at St. Joseph Mercy Hospital (SJMH), Ann Arbor, Michigan, had cardiovascular (27), endocrinologic (5), and other diseases (9). Eighteen recipients of kidney transplants at the University of Michigan Hospital formed the third patient group, and 24 normal volunteers, aged 26 to 44 years, under no continuous medication, served as controls.

The drug regimen of all the patients was recorded daily. The previous medication of the patients treated in the CRU had been unchanged at least 2 weeks prior to admission. All patients had normal liver function tests. The serum creatinine values were normal, except the transplant recipients who had elevated serum creatinines at the beginning of the investigation. Food consumption of the patients was not restricted.

Methods. The 24 hour urine collections were as follows: Patients in CRU, daily after admission for up to 3 weeks; transplant recipients, daily for up to 4 weeks after operation; and patients in SJMH, daily 5 to 7 days after admission. If the samples were not analyzed directly after the collection, they were stored at $-20^{\circ} \mathrm{C}$.

Glucaric acid (GA) in the urine was determined as described by Marsh. ${ }^{15}$ Briefly, urinary GA was converted to D- glucaro-1,4-lactone at $100^{\circ} \mathrm{C}$ and $\mathrm{pH} 2$, and the specific inhibition of $\beta$-glucuronidase (rat liver preparation) by the latter compound was determined by measuring the hydrolysis of phenolphthalein glucuronide (Sigma, St. Louis). Urine samples heat-treated at $\mathrm{pH} 8$ were used as controls. The difference in absorbance at $540 \mathrm{~nm}$ of urine samples heat-treated at acidic and alkaline $\mathrm{pH}$, respectively, was read from a standard curve, obtained by plotting per cent enzyme inhibition against various concentrations of the standard, D-glucaro-1,4lactone (Sigma). The excretion of glucaric acid is expressed as $\mu$ moles of glucaro-1,4lactone per 24 hours. If necessary, urine samples were diluted or concentrated, to produce about $50 \%$ inhibition of the enzymatic reaction.

The following drugs and classes of drugs were considered to be enzyme inducers: barbiturates, antihistamines, cortisone, prednisone, phenylbutazone, and mitotane $\left(\mathrm{o}, \mathrm{p}^{\prime}\right.$-DDD $)$. The statistical treatment of the data included the Student's $t$ test, the paired sample $t$ test, and the $F$ test.

\section{Results}

Drug therapy and glucaric acid excretion. The excretion of GA in the 41 patients (CRU) investigated after their admission averaged $19.4 \pm 12.0 \mu$ moles as compared to $13.9 \pm 4.9 \mu$ moles of the controls. The difference $(\mathrm{p}<0.05)$ and the variance in this group $(p<0.005)$ were significant. Fig. 1 shows the GA excretion in these patients in reference to previous drug therapy. GA excretion of patients treated with inducers was significantly higher than that of other patients and of the controls. The mean values of GA excretion of patients treated with noninducers and those receiving no medication did not differ from the control group.

Glucaric acid excretion during hospital treatment. Urinary GA excretion of 6 normal people was followed for 1 week. The excretion rate in these subjects ranged from 5 to $25 \mu$ moles per day, with an indi- 


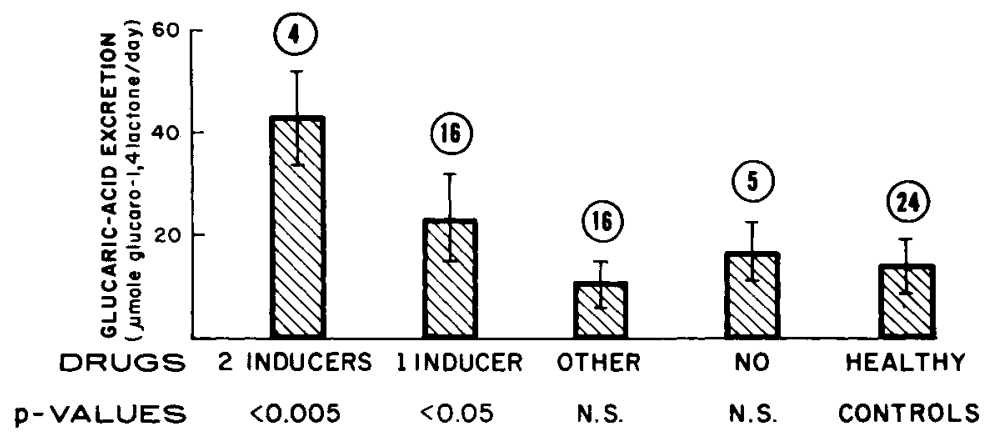

Fig. 1. Glucaric acid excretion (mean \pm S.D.) in admitted patients and in normal individuals. The patients are grouped on the basis of previous drug therapy.

vidual standard deviation of \pm 1.5 to 3.0 $\mu$ moles. The GA excretion in hospitalized patients was dependent on the drugs taken and is illustrated by the following case reports.

Patient 1. The excretion of GA increased rapidly in a 38-year-old woman with Cushing's syndrome after beginning therapy with o,p'-DDD (Fig. 2, A).

Patient 2. A daily decrease of GA excretion was noted in a 36-year-old man with celiac disease after his second admission, although no drugs were prescribed to this patient following his previous discharge from the hospital. However, the patient eventually admitted using "sleeping pills" at home (Fig. 2, B).

Patient 3. In a 47-year-old man with numerous medical problems the urinary excretion of GA decreased during the three days following his admission during which time the intake of barbiturates and analgetics were restricted. When these drugs were again administered the excretion of GA increased, followed by a decrease during a period of food restriction. After the resumption of a normal diet, the excretion of GA again increased (Fig. 2, C).

Patients 4, 5, and 6. The GA excretion varied within the normal limits in 3 female patients (aged 42, 43, and 50) with chronic rheumatic disease. During the investigation period, drug regimens of these patients were unchanged (Fig. 2, D).

Fasting and glucaric acid excretion.
Table I. Effect of fasting on glucaric acid excretion

\begin{tabular}{c|c|c|c}
\hline $\begin{array}{c}\text { Glucaric acid } \\
\text { (4moles glucaro- }\end{array}$ & & \multicolumn{2}{|c}{ Fasting (days) } \\
\cline { 3 - 4 } 1,4-lactone) & Before & 1 & 2 \\
\hline Mean & 26.2 & $18.9^{*}$ & $14.1^{\circ}$ \\
\pm S.D. & 16.3 & 13.9 & 10.6 \\
$\mathrm{n}$ & 8 & 8 & 8 \\
\hline "Decrease significant & $(\mathrm{p}<0.01) ;$ & paired & sample t
\end{tabular}
test.

Eight patients (Table I) fasted for 2 days. During that time, the GA excretion of these subjects significantly decreased below that before the food restriction.

Multiple-drug therapy and glucaric acid excretion. In 41 patients investigated during hospitalization (SJMH), the GA excretion averaged $37.6 \pm 23.1 \mu$ moles (Fig. 3). The difference between the mean GA excretion of these patients and that obtained in the control group $(p<0.001)$ and the variance in these two groups $(\mathrm{p}<0.001)$ were significant. The hospitalized patients received multiple-drug therapy $(5 \pm 2$ drugs per day). Ten patients of this group received enzyme inducers (phenobarbital $25 \mathrm{mg}$ per day, 2 cases; diphenhydramine $50 \mathrm{mg}$ per day, 6 cases; prednisone $20 \mathrm{mg}$ per day, 2 cases). GA excretion by these 10 averaged $38.9 \pm 27.6 \mu$ moles, while in the other patients of this group who received only noninducers it averaged $35.3 \pm$ 21.5. This difference is not statistically significant. 

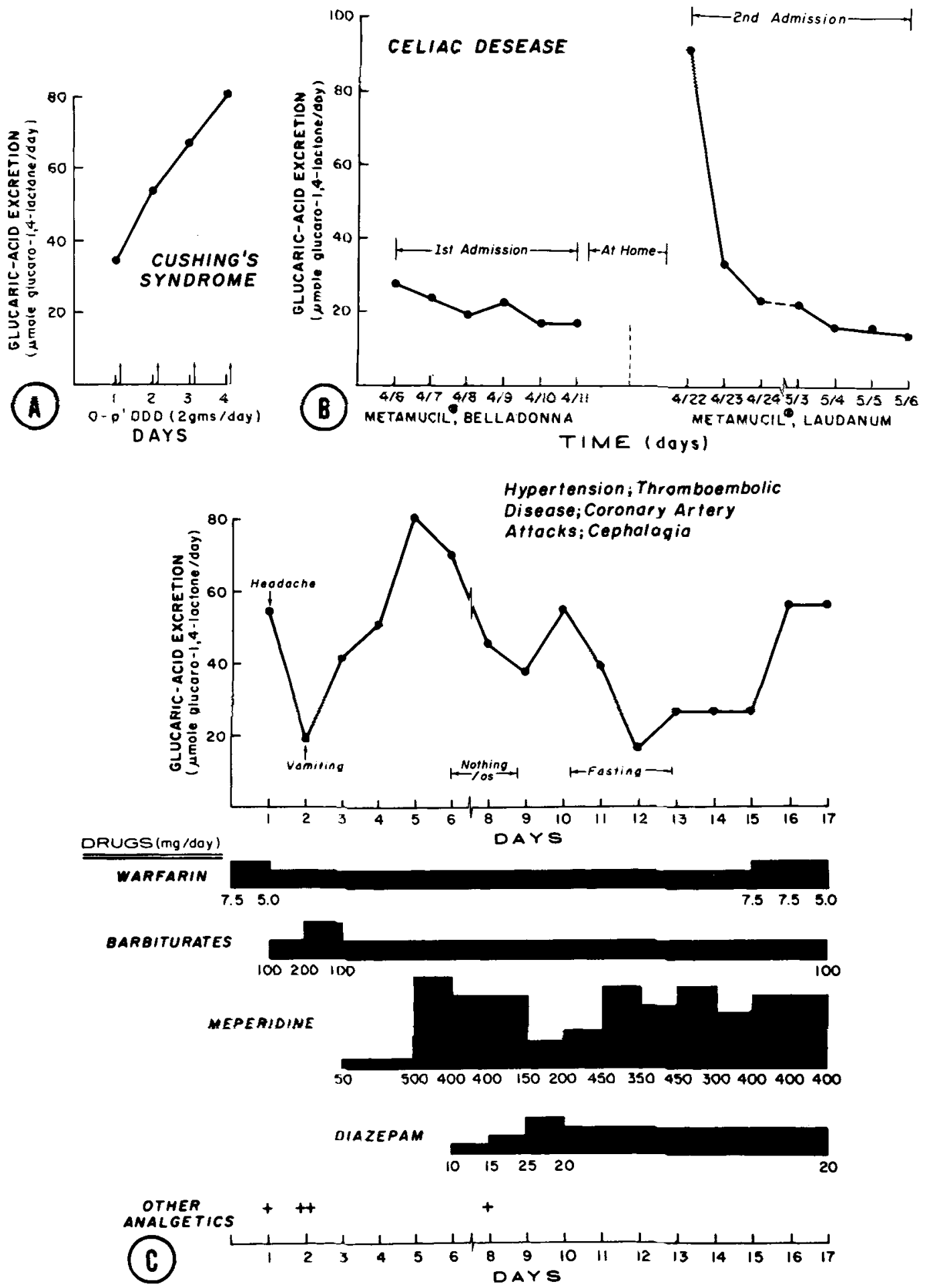

Fig. 2. $A-D$, The excretion of glucaric acid in hospitalized patients: increased excretion after the intake of an inducer ( $A$ ); decreased excretion after withdrawal of inducing drug therapy (B); variability of glucaric acid excretion depending on the cessation or onset of inducing drug therapy and of food restriction $(C)$; glucaric acid excretion in patients on unchanged drug therapy $(D)$. 


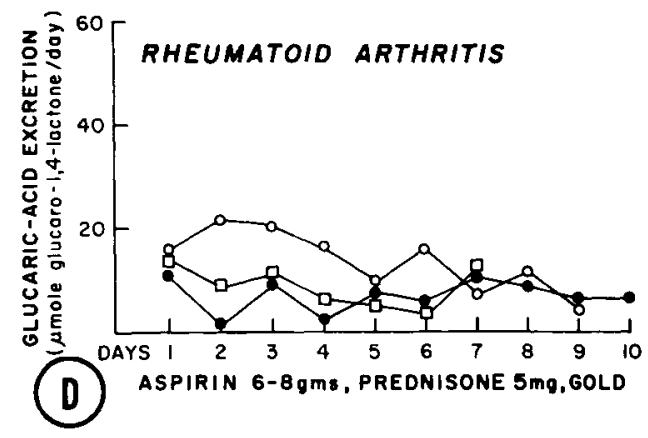

Fig. 2, D. For legend see opposite page.

Glucaric acid excretion in recipients of kidney transplants. GA excretion in 18 patients after kidney transplantation is shown in Fig. 4. Five patients receiving anticonvulsants (100 to $300 \mathrm{mg}$ diphenylhydantoin alone or in combination with 100 to $200 \mathrm{mg}$ phenobarbital) excreted more $(\mathrm{p}<0.001)$ glucaric acid during the postoperative phase than the remaining 13 in the group. The additional drug therapy for all of the 18 patients was similar: immunosuppressive drugs (azathioprine and prednisone), antibiotics, analgetics, and occasionally cathartics and tranquilizers. The GA excretion in this group was highest during 1 to 3 days following the operation and decreased thereafter. This decrease was significant in the 5 patients on anticonvulsants $(\mathrm{p}<0.01)$ but not in the others.

The urinary creatinine excretion in the 5 patients on anticonvulsants did not differ from that of others in this group.

\section{Discussion}

Marked individual differences in blood levels of drugs in patients treated in the same way have been reported for a number of compounds known to be metabolized by liver microsomes. ${ }^{13}$ Little is known about drug metabolism in hospitalized patients. ${ }^{18}$ Our results suggest that urinary glucaric acid determination is a reliable indicator of enzyme induction in patients. Our data show greater variation in GA excretion in drug-taking patients than in normals, suggesting considerable differences in their drug-metabolizing capacity.

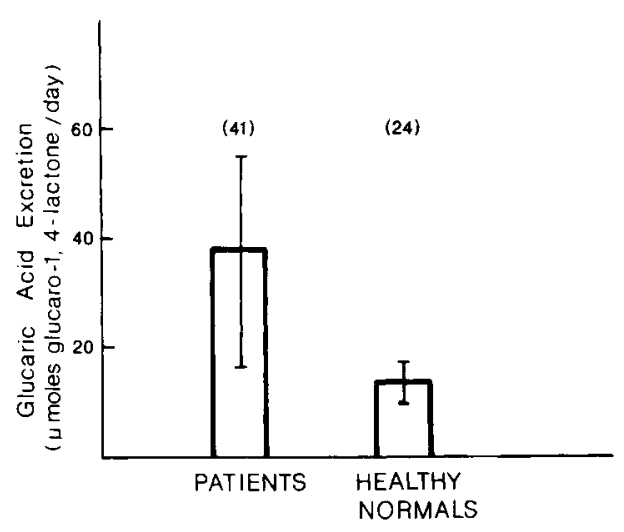

Fig. 3. Glucaric acid excretion (mean \pm S.D.) in hospitalized patients on multiple-drug therapy and in normal controls.

Glucaric acid determinations also detected the use of inducers by patients withholding information on drug use.

Drug metabolism in acutely ill patients as well as the effects of repeated doses of drug mixtures on the human drug-metabolizing capacity have not been systematically investigated. There is some evidence suggesting that hospitalization itself may stimulate drug metabolism in patients on therapy known to inhibit metabolizing enzymes. ${ }^{24}$ Our results show increased GA excretion in patients on multiple-drug therapy and a daily variation of GA excretion in patients on alternating-drug therapy. Changes in human conditions, e.g., pregnancy or malignancy, may affect the GA excretion. ${ }^{16}$

The evidence suggests that if glucaric acid determination is to be used as an indicator of enzyme induction in acutely ill patients, it must be made on serial 24 hour urine specimens. If the use of inducing drugs has to be elicited by a single determination in patients with unknown medical history, only $80 \mu$ moles per day or more of GA can be taken as substantial evidence (Fig. 5). The amount of drugs required to induce liver enzymes in man is not known nor is the response similar in all patients. Our data show that in multiple-drug treatment the effect of small doses of inducers on GA excretion may be masked, but in higher doses, such as 


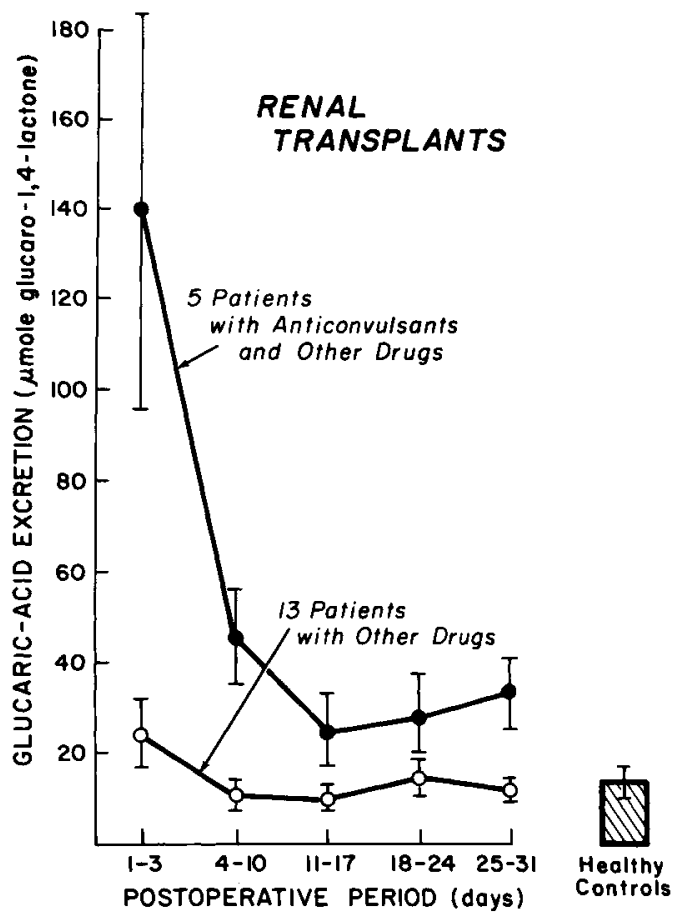

Fig. 4. Glucaric acid excretion (mean \pm S.D.) in recipients of kidney transplants after operation and in normal controls.

those of anticonvulsants capable of preventing convulsions, GA excretion is significantly increased.

Investigations in experimental animals have revealed both impairment and enhancement of drug metabolism during starvation. ${ }^{7,}{ }^{12}$ During fasting the production of glucuronides may be decreased without any impairment in the activity of enzymes involved in this pathway. ${ }^{17}$ It is therefore likely that the decreased GA excretion in our patients undergoing shortterm fasting reflects a lack of substrate in the biosynthetic pathway of GA.

The decreasing GA excretion in renal transplant patients, especially in those on anticonvulsants, probably reflects the effect of immunosuppressive drugs on the activity of GA-producing enzymes. ${ }^{3}$ The present findings agree with our previous investigations, ${ }^{21,23}$ which also revealed the importance of the sum effect of all drugs when evaluating enzyme induction in patients receiving many of them at the same time.

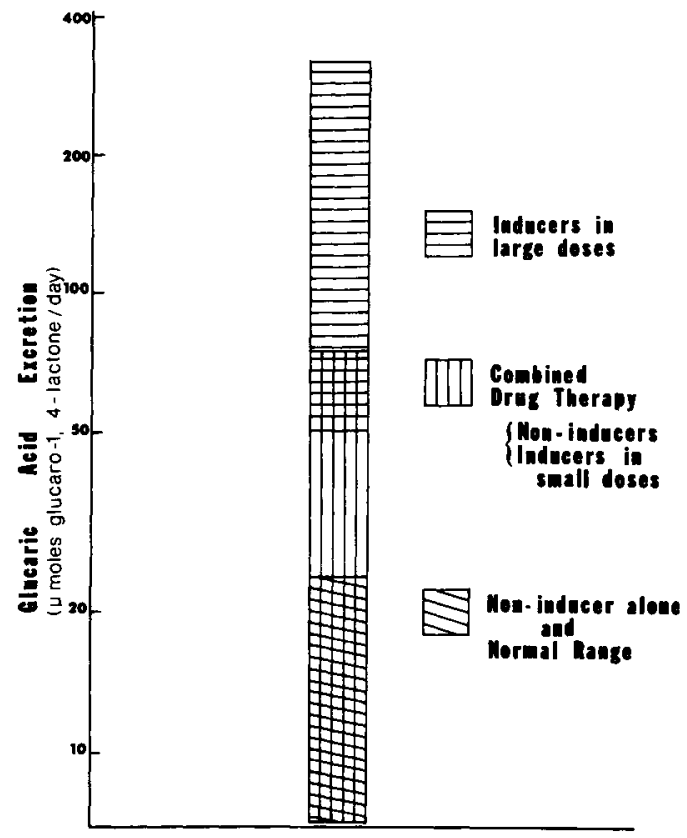

Fig. 5. Significance of a single determination of glucaric acid in a patient with unknown medical history.

It must be emphasized that increased or decreased GA excretion rates do not necessarily express the actual capacity of the liver to metabolize a drug given later. In evaluating GA determinations, the general treatment of the patient has to be considered. Since urinary GA is an end product of the glucuronic acid pathway, limited availability of corresponding substrates in a restricted diet can alter the level of GA excretion. Patients are often treated simultaneously with inducing as well as enzyme-inhibiting drugs and, since net effect of all these compounds determines the activity of the drug-metabolizing enzyme system, in some such cases GA excretion may be in normal range. Although elevated excretion rates suggest the use of enzyme-inducing drugs, such values need not necessarily correlate with an enhanced disappearance rate of a drug given later. The inducers still present in the body may inhibit the metabolism of a subsequently administered drug. Our recent studies in multiple-drug-treated rats support this view. ${ }^{25}$ 


\section{References}

1. Aarts, E. M.: Evidence for the function of Dglucaric acid as an indicator for drug enhanced metabolism through the glucuronic acid pathway in man, Biochem. Pharmacol. 14:359-363, 1965.

2. Alvares, A. P., Schilling, G., Levin, W., Kuntzman, R., Brand, L., and Mark, L. C.: Cytochrome P-450 and $b_{5}$ in human liver microsomes, Clin. Pharmacol. Ther. 10:655-659, 1969.

3. Calabresi, P., and Parks, R. E.: Chemotherapy of neoplastic diseases, in Goodman, L, S., and Gilman, A., editors: The pharmacological basis of therapeutics, New York, 1970, The Macmillan Company, pp. 1345-1395.

4. Cluff, L. E., Thoronton, G. F., and Seidl, L. G.: Studies on the epidemiology of adverse drug reactions, J. A. M. A. 188:976-983, 1964.

5. Chadewick, R. W., Cranmer, M. F., and Peoples, A. J.: Metabolic alterations by DDT administration and ascorbic acid deficiency, Toxicol. Appl. Pharmacol. 20:308-318, 1971.

6. Conney, A. H.: Pharmacological implications of microsomal enzyme induction, Pharmacol. Rev, 19:317-366, 1967.

7. Dixon, R. L., Shultice, T. W., and Fouts, J. R.: Factors affecting drug metabolism by liver. Starvation, Proc. Soc. Exp. Biol. Med. 103:333-335, 1960.

8. Dutton, G. J.: Glucuronic acid, free and combined, New York, 1966, Academic Press, Inc.

9. Fahim, M. S., Hall, D. G., and Fahim, Z.: Urinary D-glucaric acid. An index of hepatic microsomal enzyme activity in human females, Am. J. Obstet. Gynecol. 105: 124-126, 1969.

10. Hunter, J., Carella, M., Maxwell, J. D., Stewart, D. A., and Williams, R.: Urinary D-glucaric acid excretion as a test for hepatic enzyme induction in man, Lancet 1:572-575, 1971.

11. Hunter, J., Maxwell, J. D., Stewart, D. A., Parsons, V., and Williams, R.: Altered calcium metabolism in epileptic children on anticonvulsants, Br. Med. J. 4:202-204, 1971.

12. Kato, R., and Gillette, J. R.: Effect of starvation on NADPH-dependent enzymes in liver microsomes of male and female rats, J. Pharmacol. Exp. Ther. 150:279-289, 1965.

13. Koch-Wester, J.: Drug therapy. Serum drug concentrations as therapeutic guides, N. Engl. J. Med. 287:227-231, 1972.

14. Lieber, C. S., and DeCarli, L. M.: The role of hepatic microsomal ethanol oxidizing system (MEOS) for ethanol metabolism in vivo, J. Pharmacol. Exp. Ther, 181:279-287, 1972.

15. Marsh, C. A.: Metabolism of D-glucuronolactone in mammalian systems, Biochem. J. 86:77$86,1963$.

16. Marsh, C. A., and Carr, A. J.: Changes in enzyme activity, related to $\mathrm{D}$-glucaric acid synthesis, with age, pregnancy and malignancy, Clin. Sci. 28:209-217, 1965.

17. Miettinen, T. A., and Leskinen, E.: Enzyme levels of glucuronic acid metabolism in the liver, kidney and intestine of normal and fasted rats, Biochem. Pharmacol. 12:565-575, 1963.

18. Prescott, L. F.: Drug metabolism and therapeutics, Scott. Med. J. 16:121-129, 1971.

19. Ritchel, W. A.: Biological half-lives of drugs, Drug Intelligence 4:332-347, 1970.

20. Schoene, B., Fleischmann, R, A., Remmer, H., and v. Olderhausen, H. F.: Determination of drug metabolizing enzymes in needle biopsies of human liver, Eur. J. Clin. Pharmacol. 4: $65-73,1972$.

21. Sotaniemi, E., Hokkanen, O., and Kaipainen, W. J.: Hepatic injury and multiple drug treatment, Ann. Clin. Res. 3:220-225, 1971.

22. Sotaniemi, E., and Palva, I. P.: The use of polypharmaceutical drug therapy in a medical ward, Ann. Clin. Res. 4:158-164, 1972.

23. Sotaniemi, E. A., Hakkarainen, H. K., Puranen, I. A., and Lahti, R. O.: Radiologic bone changes and hypocalcemia with anticonvulsant therapy in epilepsy, Ann. Intern. Med. 77: 389-394, 1972.

24. Sotaniemi, E. A., Kontturi, M. J., and Larmi, T. K.: Drug metabolism and androgen control therapy in prostatic cancer, Clin. PHarMacol. Ther. 14:413-417, 1973.

25. Sotaniemi, E. A., and Medzihradsky, F.: Effects of multiple drug pretreatment on drug levels in blood and tissues, Fed. Proc. 32:701, 1973.

26. Vesell, E. S., and Page, J. C.: Genetic control of the phenobarbital-induced shortening of plasma antipyrine half-lives in $\operatorname{man}_{3}$ I. Clin. Invest. 48:2202-2209, 1969.

27. Vesell, E. S., Page, J. G., and Passananti, G. T.: Genetic and environmental factors affecting ethanol metabolism in man, Curn. PharMACOL. THER. 12:192-201, 1971.

28. Williams, R., Maxwell, J. D., and Hunter, J: Some clinical implications of hepatic enzyme induction, Excerpta Medica Int. Cong. Ser. 13: 44-51, 1972. 